\title{
CIRURGIA CORRETIVA DE FRATURA DE ARCO ZIGOMÁTICO COM A TÉCNICA DE GILLIES: RELATO DE CASO CLÍNICO
}

Marcelo ÁRSEGO, Leandro KLUPPEL, Delson COSTA, Nelson REBALLATO, Paulo MÜLLER

O arco zigomático é um componente estrutural do complexo zigomático formado pela junção do processo zigomático do temporal com o processo temporal do zigomático. Em função de sua estrutura frágil e sua posição, traumas de baixa intensidade perpendiculares a ele podem levar a fraturas. As fraturas do arco zigomático compreendem quase $10 \%$ dos casos de fraturas do complexo e resultam em uma deformidade angular típica. Estas podem ser classificadas em classe I (fratura em "V"), classe II (fratura com fragmento intermediário), classe III (fratura combinada do osso malar e do arco zigomático) no intuito de orientar o cirurgião no planejamento bem como no tratamento. Os pacientes podem apresentar sinais e sintomas como depressão ou abaulamento na topografia do arco e limitação da abertura bucal. Diversos tratamentos já estão bem estabelecidos na literatura, cada qual com sua indicação específica, sendo o método de Gillies um dos mais usados para redução de tais fraturas. $O$ presente estudo relata um caso clínico de fratura de arco zigomático utilizando o acesso de Gillies, expondo o pré, o trans e o pós operatório.

Palavras-chave: Fratura, Osso Zigomático, Arco Zigomático. 